J. Dairy Sci. 99:7481-7488

http://dx.doi.org/10.3168/jds.2015-10703

(C) 2016, THE AUTHORS. Published by FASS and Elsevier Inc. on behalf

of the American Dairy Science Association ${ }^{\circledR}$. This is an open access article under

the CC BY-NC-ND license (http://creativecommons.org/licenses/by-nc-nd/3.0/).

\title{
Short communication: Pilot study on hormonal, metabolic, and behavioral stress response to treatment of claw horn lesions in acutely lame dairy cows
}

\author{
S. Janßen, ${ }^{* 1}$ C. Wunderlich, ${ }^{11,2}$ M. Heppelmann, ${ }^{*}$ R. Palme, $†$ A. Starke,‡ W. Kehler, ${ }^{*}$ A. Steiner,§ A. Rizk,\# \\ U. Meyer,II S. Daenicke,Il and J. Rehage* \\ ${ }^{*}$ Clinic for Cattle, University of Veterinary Medicine, 30173 Hannover, Germany \\ †Department of Biomedical Sciences, University of Veterinary Medicine, 2010 Vienna, Austria \\ ‡Department of Large Animal Medicine, Faculty of Veterinary Medicine, University of Leipzig, 04103 Leipzig, Germany \\ $\S$ Clinic for Ruminants, Vetsuisse-Faculty, University of Berne, 3001 Berne, Switzerland \\ \#Surgery, Anaesthesiology and Radiology Department, Faculty of Veterinary Medicine, Mansoura University, 35516 Mansoura, Egypt \\ IIInstitute of Animal Nutrition, Friedrich-Loeffler-Institute, Federal Research Institute for Animal Health, 38116 Braunschweig, Germany
}

\begin{abstract}
Short-term effects of therapeutic claw trimming in acutely lame cows $(\mathrm{n}=21)$ with nonadvanced claw horn lesions on the endocrine, metabolic, and behavioral stress responses were investigated in comparison to regular claw trimming in nonlame control cows $(\mathrm{n}=$ 21). Controls were matched to lame cows by parity and stage of lactation. Lame cows suffering from typical sole ulcers or white line disease were blinded and randomly assigned to 2 treatments, receiving $15 \mathrm{~min}$ before interventions either ketoprofen $(\mathrm{n}=11 ; 3 \mathrm{mg} / \mathrm{kg}$ of BW intramuscularly; Romefen, Merial, Lyon, France) or placebo $(\mathrm{n}=10$; saline in equivalent amount and route of administration). All cows underwent functional claw trimming in lateral recumbency on a surgical tipping table, and claw horn lesions in lame cows were conventionally treated (removal of loose horn, block on opposing claw, bandaging of affected claw). Blood samples collected $15 \mathrm{~min}$ before, at the end, and $24 \mathrm{~h}$ after claw trimming were analyzed for concentrations of cortisol, fatty acids, lactate, and glucose, and fecal samples (collected before treatment and after 24 h) for cortisol metabolites. Behavioral stress responses during functional and therapeutic claw trimming were recorded. Concentrations of blood cortisol, fatty acids, glucose, and fecal cortisol metabolites were higher in lame than in nonlame cows after treatment. During claw treatment, more leg movements were recorded for lame cows than nonlame cows. Pre-emptive administration of ketoprofen had no obvious effects on stress responses to therapeutic claw trimming. Treatments of claw horn lesions caused a significant stress and pain reaction in acutely lame cows, demonstrating the neces-
\end{abstract}

Received December 1, 2015.

Accepted May 21, 2016.

${ }^{1}$ These authors contributed equally to this work.

${ }^{2}$ Corresponding author: Christian.Wunderlich@tiho-hannover.de sity of adequate pain management protocols for such interventions.

Key words: lameness, dairy, stress response, pain, animal welfare

\section{Short Communication}

With prevalence rates ranging from 25 to $40 \%$, lameness is a frequent health disorder in dairy herds (Barker et al., 2010; Main et al., 2010). Lameness is mainly caused by claw horn lesions or inflammatory alterations of the adjacent soft tissues (Murray et al., 1996). Claw horn lesions, such as sole ulcers and white line disease, are painful (Rushen et al., 2007; Nechanitzky et al., 2016) due to inflammation and compression of the corium in the affected region (Van Amstel and Shearer, 2006). Such lesions are commonly treated in early stages by claw trimmers during regular claw trimming. The treatment includes removal of loose horn and provision of a smooth transition to the healthy horn. Only the non-pain-sensitive horn in the area of the defect is supposed to be pared off (Toussaint Raven, 2003), and the inflamed corium remains untouched. Afterward, the inflamed and sensitive corium is exposed and protected against mechanical irritation and pressure by a bandage and removing weight bearing from the afflicted claw through the application of a block to the opposing claw (Blowey, 1990).

Generally, professionals agree that major surgeries such as amputation or resection of the distal interphalangeal joint in case of advanced stages of claw horn lesions demand local anesthesia and administration of analgesics to control postoperative pain (Desrochers and St Jean, 1996; Heppelmann et al., 2009; Becker et al., 2013; Offinger et al., 2013). However, assuming that in most instances lame cows are treated by professional claw trimmers or stockmen, therapeutic claw trimming in cows with nonadvanced claw horn lesions is normally done under restraint without any sedation, anesthesia, 
Table 1. Production data (means \pm SEM) of lame cows treated either with ketoprofen or placebo (saline) and of nonlame control cows

\begin{tabular}{|c|c|c|c|c|c|c|}
\hline Group & $\mathrm{n}$ & $\begin{array}{l}\mathrm{BW} \\
(\mathrm{kg})\end{array}$ & $\begin{array}{l}\text { Age } \\
(\mathrm{yr})\end{array}$ & Parity & DIM & $\begin{array}{c}\text { Milk } \\
\text { yield }(\mathrm{kg} / \mathrm{d})\end{array}$ \\
\hline \multicolumn{7}{|l|}{ Lame } \\
\hline Ketoprofen & 11 & $\begin{array}{l}661 \pm 17 \\
(589-724)\end{array}$ & $\begin{array}{c}6.3 \pm 0.5 \\
\quad(4-9)\end{array}$ & $\begin{array}{c}4.3 \pm 0.5 \\
(2-7)\end{array}$ & $\begin{array}{c}187 \pm 21 \\
(73-296)\end{array}$ & $\begin{array}{l}30.9 \pm 0.4 \\
\quad(18.8-50.4)\end{array}$ \\
\hline Placebo & 10 & $\begin{array}{l}650 \pm 15 \\
(612-710)\end{array}$ & $\begin{array}{c}5.3 \pm 0.4 \\
\quad(4-7)\end{array}$ & $\begin{array}{c}3.3 \pm 0.4 \\
(2-5)\end{array}$ & $\begin{array}{r}178 \pm 28 \\
(19-277)\end{array}$ & $\begin{array}{l}30.2 \pm 0.4 \\
\quad(16.9-49.5)\end{array}$ \\
\hline Controls & 21 & $\begin{array}{l}686 \pm 16 \\
(594-819)\end{array}$ & $\begin{array}{c}5.5 \pm 0.3 \\
(4-9)\end{array}$ & $\begin{array}{c}3.5 \pm 0.3 \\
(2-7)\end{array}$ & $\begin{array}{r}180 \pm 16 \\
(22-283)\end{array}$ & $\begin{array}{l}29.9 \pm 0.3 \\
\quad(13.1-52.9)\end{array}$ \\
\hline
\end{tabular}

or analgesia (O'Callaghan et al., 2002; Whay et al., 2005; Becker et al., 2014). However, most veterinarians judge such procedures as painful for the affected cows and would clearly use anesthesia for the same intervention in horses (O'Callaghan-Lowe et al., 2004b).

In cattle, ketoprofen is a commonly used nonsteroidal anti-inflammatory drug (NSAID) that demonstrated analgesic properties in the posttherapeutic claw trimming period in dairy cows after claw treatment in different studies (Feist et al., 2008; Flower et al., 2008; Chapinal et al., 2010; Thomas et al., 2015).

Inadequate pain control for treatment of lame cows is a growing concern (Huxley, 2012; Potterton et al., 2012; Shearer et al., 2013). The hypothesis of this exploratory study was that claw trimming and treatment of claw horn lesions is a painful procedure for acutely and mildly lame dairy cows, and that it will induce a more pronounced hormonal, metabolic, and behavioral stress response than claw trimming alone in nonlame cows. A secondary aim was to gain information if analgesic effects of pre-surgically administered ketoprofen might attenuate stress responses in lame cows undergoing therapeutic claw trimming.

A total of 42 pluriparous German Holstein dairy cows in mid lactation of one research herd which were used to close animal-human contact were studied (Table 1; data from daily herd recordings; BW was measured automatically after milking). Cows were kept in a free stall with cubicles and were fed a typical ration based on corn and grass silage with concentrate according to performance. Twice weekly, all cows were scored for lameness by the same person, using a scale from 0 to 5 (0 meaning no lameness, 5 meaning no weight on the affected leg; Sprecher et al., 1997).

Twenty-one cows with lameness in one hind limb, a lameness score of $\geq 2$ (Table 2), and a claw horn lesion (typical sole ulcer: $\mathrm{n}=11$; white line disease: $\mathrm{n}=10$ ) were enrolled and matched each with a nonlame control cow $(\mathrm{n}=21)$ from the same herd according to parity and stage of lactation. During clinical examination in all cows, no health disorders were present in lame cows other than the claw horn lesions. In blinded mode, lame cows were treated according to a randomization list either with ketoprofen ( $\mathrm{n}=10$; Romefen, Merial, Lyon, France; $3 \mathrm{mg} / \mathrm{kg}$ of BW intramuscularly) or placebo ( $\mathrm{n}=11$; saline, equivalent amount and route of administration) 15 min before claw trimming in lateral recumbency (LR) on a hydraulic surgical tipping table (Rizk et al., 2012a). The nonlame cows also received placebo treatment before claw trimming.

Claw trimming was performed according to the Dutch method (Toussaint Raven, 2003) by a veterinarian

Table 2. Frequency distribution of locomotion scores in lame cows either treated with placebo $(\mathrm{n}=11)$ or ketoprofen $(\mathrm{n}=10)$ before, immediately after, and $24 \mathrm{~h}$ after therapeutic claw trimming (score $0-5$ according to Sprecher et al., 1997) ${ }^{1}$

\begin{tabular}{|c|c|c|c|c|}
\hline \multirow[b]{2}{*}{ Treatment group } & \multirow{2}{*}{$\begin{array}{l}\text { Relative to claw } \\
\text { trimming }\end{array}$} & \multicolumn{2}{|c|}{$\begin{array}{l}\text { Locomotion } \\
\text { score }\end{array}$} & \multirow{2}{*}{$\begin{array}{c}\text { Group effect } \\
P \text {-value }\end{array}$} \\
\hline & & 2 & 3 & \\
\hline $\begin{array}{l}\text { Placebo } \\
\text { Ketoprofen }\end{array}$ & Before & $\begin{array}{l}5 \\
6\end{array}$ & $\begin{array}{l}6 \\
4\end{array}$ & 0.67 \\
\hline $\begin{array}{l}\text { Placebo } \\
\text { Ketoprofen }\end{array}$ & After & $\begin{array}{l}9 \\
9\end{array}$ & $\begin{array}{l}2 \\
1\end{array}$ & 1.0 \\
\hline $\begin{array}{l}\text { Placebo } \\
\text { Ketoprofen }\end{array}$ & $24 \mathrm{~h}$ after & $\begin{array}{r}11 \\
8\end{array}$ & $\begin{array}{l}0 \\
2\end{array}$ & 0.21 \\
\hline
\end{tabular}

${ }^{1}$ Only scores 2 and 3 were observed; overall time effect: $P=0.010$, time effect within placebo group: $P=0.013$, time effect within ketoprofen group: $P=0.43$. 
[M.H.] to promote correct weight bearing by reshaping the claw horn capsule. Length and sole thickness were corrected with a grinder; paring and sloping of the claws were done using hoof knives. In the area of claw horn lesions, damaged and underrun horn was pared away with a hoof knife and a smooth transition from the affected area to the healthy horn was provided. The corium was left untouched and spared from pressure during the procedure. To remove weight bearing from the affected claw, a wooden block (Demotec 95; Demotec, Nidderau, Germany) was attached to the healthy opposing claw (O'Callaghan-Lowe et al., 2004b). Although not implicitly necessary (Pyman, 1997), a bandage was applied to protect lesions from dirt. For bandaging, the lesions were covered by tailored gauze soaked with Lotagen Gel as a biocide (18 mg/g; Policresulen, Essex/ MSD, Munich, Germany). As padding, $150 \mathrm{~mm}$ wide cotton wool (Noba Verbandmittel, Wetter, Germany) was wrapped around the treated claw, fixed with 120 mm wide elastic bandage (Noba Verbandmittel) and 19 mm wide adhesive tape (Tesa 4541, Tesa, Norderstedt, Germany) and protected against moisture with wood tar. Control cows received claw trimming on a surgical tipping table. Duration for restraint and claw trimming in control cows was adjusted according to the time the matched lame cow lay on the tipping table for claw trimming and treatment of claw horn lesions.

The study was approved by the Ethical Animal Care and Use Committee of the Federal State of Lower Saxony, Germany (permit number 33.11.42502-05A016/07).

Blood samples were collected from a jugular vein in serum (28.364, no additive, Sarstedt, Nürnbrecht, Germany) and fluoride tubes (36.339 containing $2 \mathrm{mg}$ of fluoride and 32 IE of heparin, Sarstedt) before medical treatments and claw trimming, at the end of the period in LR, and $24 \mathrm{~h}$ later by venipuncture. Fluoride samples were stored on ice until centrifugation. Blood samples were centrifuged $\left(1,500 \times g, 15 \mathrm{~min}, 4^{\circ} \mathrm{C}\right)$ within 60 min after collection. Fecal samples were collected before the first blood sample was taken and $24 \mathrm{~h}$ later. All samples were stored at $-80^{\circ} \mathrm{C}$ until analysis. Lameness was scored before and after the cows were restrained and again $24 \mathrm{~h}$ later.

Behavior on the surgery table was recorded as (1) vocalization (score 1-3: score 1: $\leq 1$, score $2: 2-3$, and score $3:>3$ vocalizations during LR), (2) movements of the treated leg (mild twitches or attempted adduction during manipulations; frequency per $5 \mathrm{~min}$ ), and (3) body movements (simultaneous movements of more than the treated leg, body and neck twisting; frequency per $5 \mathrm{~min}$ ), without further differentiating the magnitude of movements.
In serum samples, cortisol was analyzed using the chemiluminescent enzyme immunoassay Immulite 1000-Test (Siemens Medical Solutions Diagnostics, Munich, Germany). Concentrations of glucose and lactate were analyzed in fluoride plasma and concentrations of fatty acids in serum using commercial test kits (Horiba ABX, Montpellier, France; Randox, Ardmore, UK; Wako Chemicals, Neuss, Germany; mti diagnostics GmbH, Idstein, Germany) within an automated analyzer (ABX Pentra 400, Horiba ABX). Concentrations of fecal cortisol metabolites were determined with an 11-oxoetiocholanolone enzyme immunoassay (Palme and Möstl, 1997), which has been validated for cattle (Palme et al., 1999).

Results were statistically evaluated by SAS version 9.3 (SAS Institute Inc., Cary, NC). Results of blood and fecal parameters deviated from normal distribution (Shapiro-Wilk Test) and were therefore common logtransformed. The effects time, status, status $\times$ time, treatment, and treatment $\times$ time were analyzed using PROC MIXED with repeated statement. Time (before, after, and $24 \mathrm{~h}$ after claw treatment), status (lame vs. nonlame cows), and treatment (ketoprofen vs. placebo) were defined as fixed effects; cow was specified as a random term. The Bayesian-Schwarz criterion and Akaike information criterion were used to determine the optimal covariance structure matrix (lactate, cortisol, and glucose: heterogeneous compound symmetry; fecal cortisol metabolites: compound symmetry; fatty acids: first-order ante-dependence) to be used in the repeated statement (Littell et al., 2000). Behavior examinations were tested nonparametrically by means of the Wilcoxon rank-sum test and lameness scores by Fisher's exact test for statistical differences in results. Because of the low number of lame cows split into a placebo and ketoprofen group, testing for medical treatment effects on stress responses has only an exploratory character. Multiple comparisons of means were adjusted using the Tukey-Kramer method. Significance level was set at $P$ $<0.05$, and a statistical trend was assumed at $0.05<$ $P<0.1$. Laboratory data are presented as box-andwhisker plots with median, 25/75 percentiles (box), $5 / 95$ percentiles (whiskers), and outliers (dots).

Overall, in lame cows lameness scores were significantly reduced after therapeutic claw trimming (Table 2; overall time effect: $P=0.010$, relative to trimming: immediately after and $24 \mathrm{~h}$ after vs. before: $P=0.043$ and $P=0.015$, respectively). An overall time effect was detected within the placebo $(P=0.013)$ but not within the ketoprofen-treated lame cows $(P=0.43)$. Neither vocalization scores during treatments on the surgery table [lame cows: (mean \pm SD) $0.8 \pm 0.7$, control cows: $0.6 \pm 0.6, P=0.48]$ nor strong whole body movements 
(lame cows: $1.3 \pm 0.5 / 5 \mathrm{~min}$, control cows: $1.0 \pm 0.2$ $/ 5 \mathrm{~min}, P=0.15)$ were different between lame and nonlame cows. The mean frequency of movements of treated legs differed between lame $(8.4 \pm 6.5 / 5 \mathrm{~min})$ and nonlame cows $(4.5 \pm 4.0 / 5 \mathrm{~min} ; P=0.048)$.

Blood cortisol and metabolite as well as fecal cortisol metabolite analysis (Figure 1) revealed in lame and nonlame cows significant time effects $(P<0.01)$ with higher values after claw treatment compared with baseline. Lameness effects were seen for serum cortisol $(P=0.034)$, fatty acids $(P=0.003)$, and fecal cortisol metabolites $(P=0.037)$, whereas lameness $\times$ time interactions were found for blood cortisol $(P=0.029)$, glucose $(P=0.006)$, and fatty acids $(P=0.004)$. Before claw treatments, average serum cortisol $(P=0.079)$ and $24 \mathrm{~h}$ after claw treatments fecal cortisol metabolite concentrations tended to be greater $(P=0.057)$ in lame cows compared with nonlame controls. Immediately after claw treatments, average serum cortisol $(P=0.046)$ and fatty acid $(P<0.001)$ concentrations were greater in lame than in nonlame cows. Average fecal cortisol metabolite concentrations were greater $24 \mathrm{~h}$ after claw treatment $(P=0.003)$ compared with baseline values in lame cows.

In lame cows, no significant effects of pre-surgical ketoprofen treatment were found on either blood concentrations of cortisol and metabolites (Figure 2) nor on behavior responses during claw lesion treatments (mean $\pm \mathrm{SD}$; vocalization: ketoprofen: $0.9 \pm 0.8$, placebo: $0.7 \pm 0.6 ; P=0.61$; whole body movements: ketoprofen: $1.3 \pm 0.6 / 5 \mathrm{~min}$, placebo: $1.2 \pm 0.4 / 5$ min; $P=0.76$; leg movements: ketoprofen: $8.5 \pm 6.6 / 5$ min, placebo: $8.3 \pm 6.7 / 5 \mathrm{~min} ; P=0.95)$. However, a statistical trend existed for higher fecal concentrations of cortisol metabolites (ketoprofen effect: $P=0.092$ ) with numerically greater concentrations in placebo than in ketoprofen-treated lame cows. After therapeutic claw trimming, serum concentrations of fatty acids $(P=0.002)$ were significantly greater in ketoprofen compared with placebo-treated lame cows (treatment $\times$ time interaction: $P=0.035$ ).

Both nonlame control cows and lame cows expressed signs of general discomfort while fixed on a surgery table for claw trimming and treatment, respectively, as expressed by vocalization and body movements. However, compared with control cows, lame cows attempted more frequently to pull their fixed legs away while they were treated. In this study, cows were not treated with the $\alpha 2$-agonist xylazin as suggested for nervous animals by Rizk et al. (2012b) before being turned into LR for claw treatments, to allow unaffected expression of behavioral, hormonal, and metabolic stress responses during treatments. Thus, the observed more frequent leg movements in lame compared with control cows can be interpreted as a sign of pronounced discomfort provoked by treatment of the claw horn lesions.

Restraining in LR induces stress in cows due to associated close human animal contact, isolation from herd mates, exposure to unfamiliar environment, technical machines, and the manipulations during claw trimming. Cows respond with release of stress hormones such as cortisol and epinephrine which are associated with a metabolic stress response (Pesenhofer et al., 2006; Rizk et al., 2012a,b), reflected in this study by an increase in blood concentrations of cortisol, glucose, fatty acids, and lactate. Before cows were turned into LR, the lame cows presented slightly higher serum cortisol concentrations than nonlame cows. This may indicate a stress response due to pain caused by the claw horn lesions (El-Ghoul and Hofmann, 2002; Mellor and Stafford, 2004; Rushen et al., 2007).

In lame cows after therapeutic claw trimming, a stronger hormonal and metabolic stress response was found compared with regularly trimmed nonlame control cows as indicated by the significant group $\times$ time interactions for cortisol, glucose, and fatty acid blood concentrations. Furthermore, higher concentrations of cortisol metabolites in fecal samples collected the day after the therapeutic claw trimming were found in lame compared with control cows. Concentrations of fecal cortisol metabolites reflect longer lasting effects of stress events on cortisol release (Ganswindt et al., 2010; Palme, 2012). In both groups, the procedure of turning cows into LR, duration of LR, and manipulations at the claws for claw trimming using an electrical grinder and hoof knives was similar. The major difference in the intervention technique was the removal of the horn in the area of the lesion in lame cows. Thus, the stronger hormonal and metabolic responses in lame cows indicate that cows experienced pain during treatment of claw horn lesions. In this study after finishing therapeutic claw trimming, affected claws were bandaged with policresulen as a topical wound dressing, and a block was attached to the opposing claw. To the authors' knowledge, no evidence has been published that bandaging or topical dressing of lesions induces pain in cows. Blocks on sound opposing claws alter locomotion behavior (Cutler et al., 2015) but likely provoke no pain during application. However, because only lame cows were bandaged and received blocks, it cannot be excluded that these manipulations induced a stress response in addition to the interventions during claw trimming. For distinction of stress responses on therapeutic claw trimming, bandaging with wound dressing, and blocking, more blood samples related to the different intervention steps possibly would have provided more detailed information. 
a
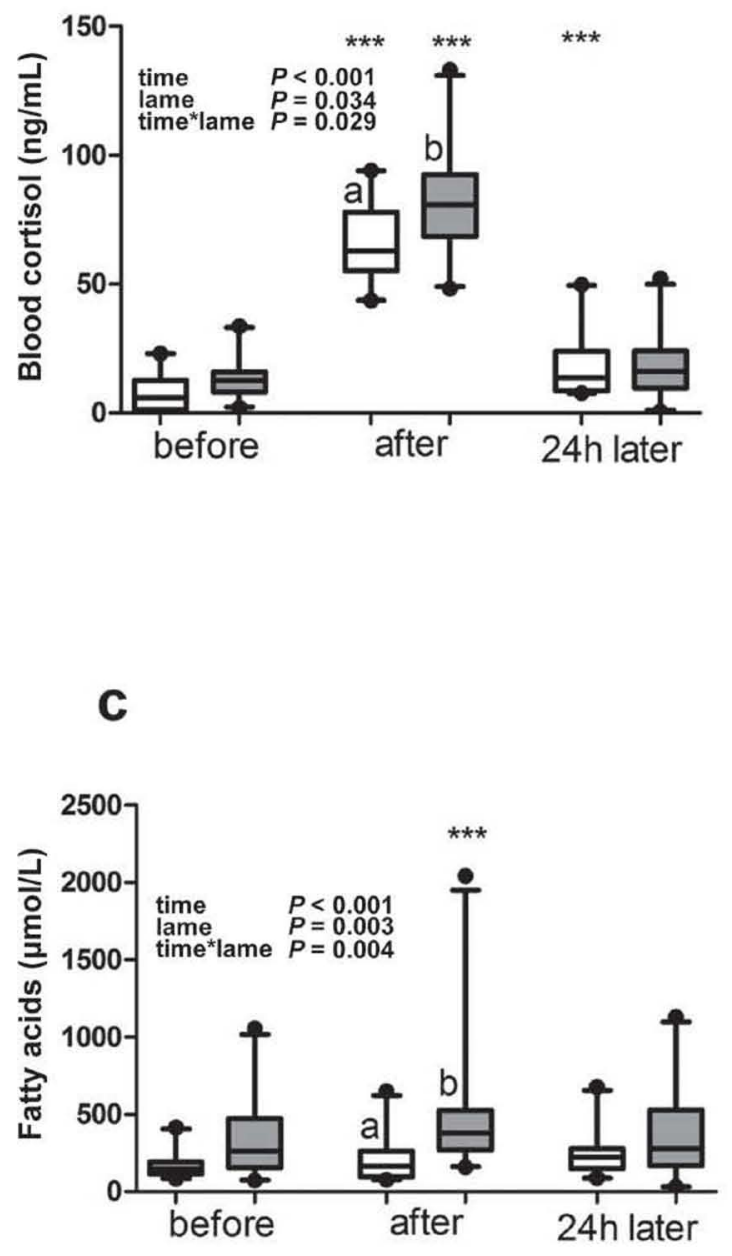

b

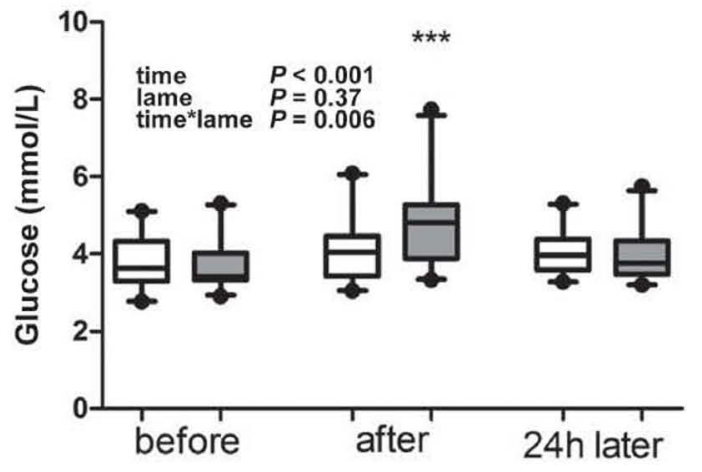

d

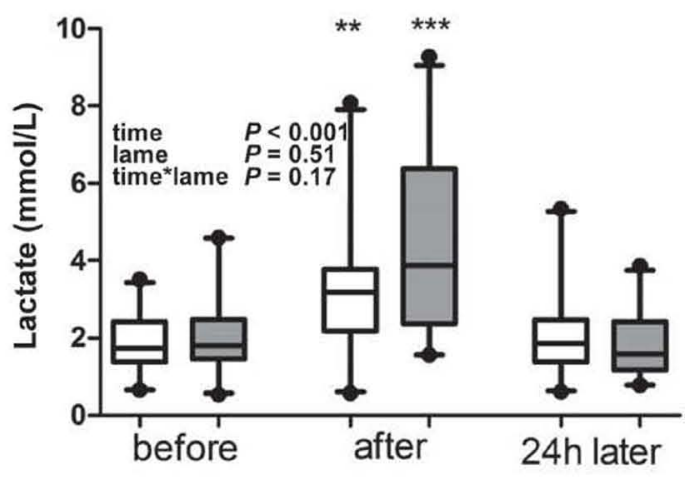

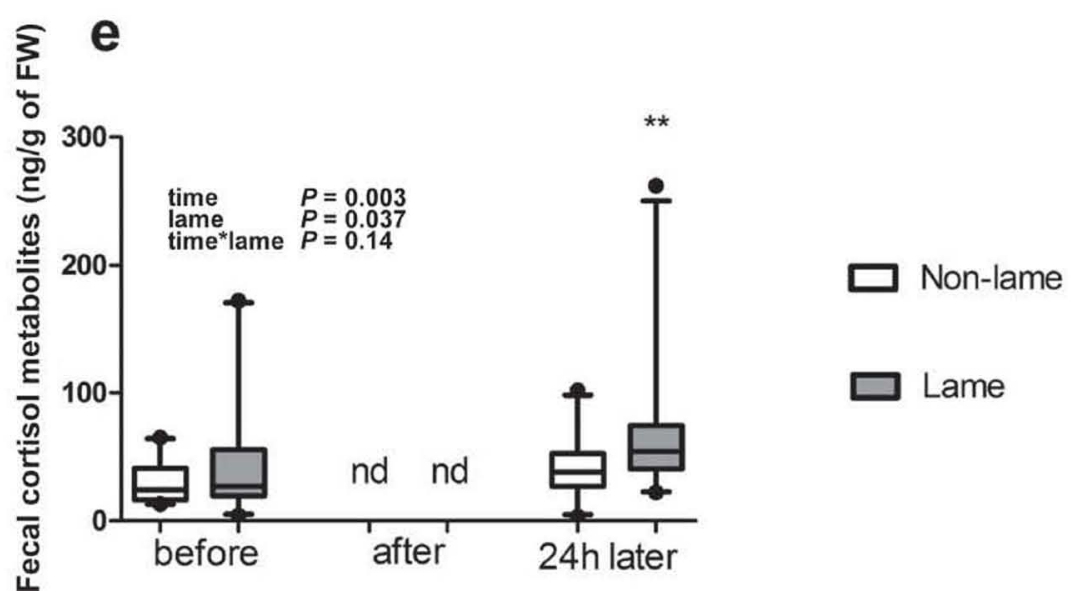

Figure 1. Box-and-whisker plots (median, box: 25/75 percentile, whisker: $5 / 95$ percentile, dot: outlier) of concentrations of blood cortisol (a), glucose (b), fatty acids (c), lactate (d), and fecal cortisol metabolites (e) in lame ( $\mathrm{n}=21)$ and nonlame (n = 21) cows. Time line: before: 15 min before intervention; after: end of lateral recumbency; $24 \mathrm{~h}$ after: $24 \mathrm{~h}$ after claw treatment. FW: fresh weight; nd: not determined. Significant difference in means at specific time points to baseline within group $\left({ }^{* * *} P<0.001 ;{ }^{* *} P<0.01\right)$. Different letters $(\mathrm{a}, \mathrm{b})$ indicate significant $(P \leq$ $0.05)$ differences within group at a specific time point. Global $P$-values (time, lameness, and interactions) are indicated within graphs. 
a

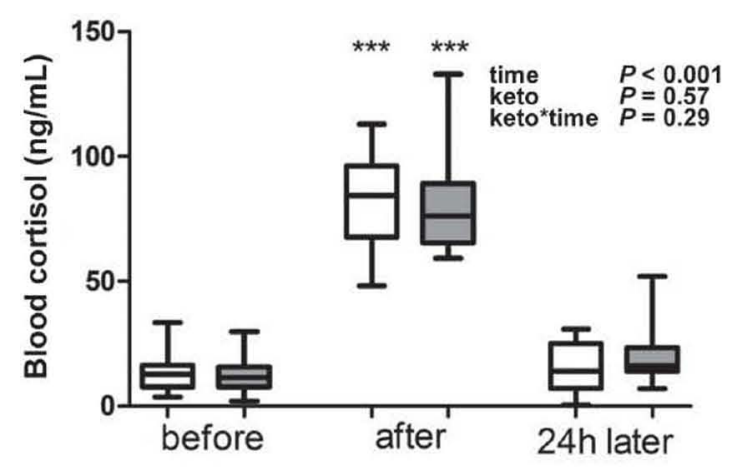

C

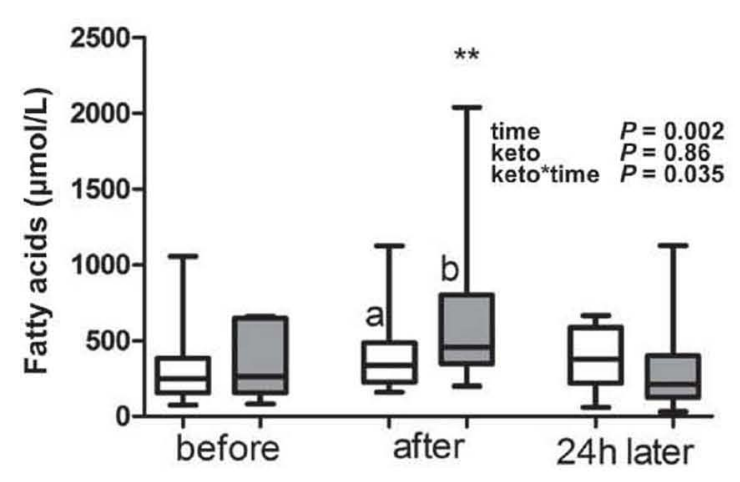

b

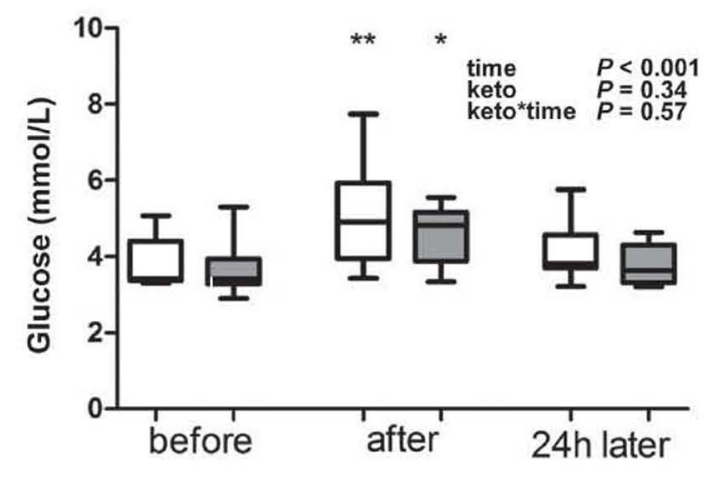

d

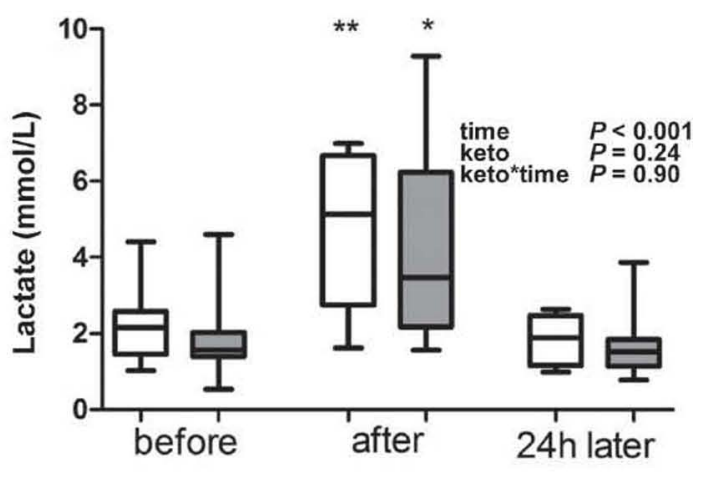

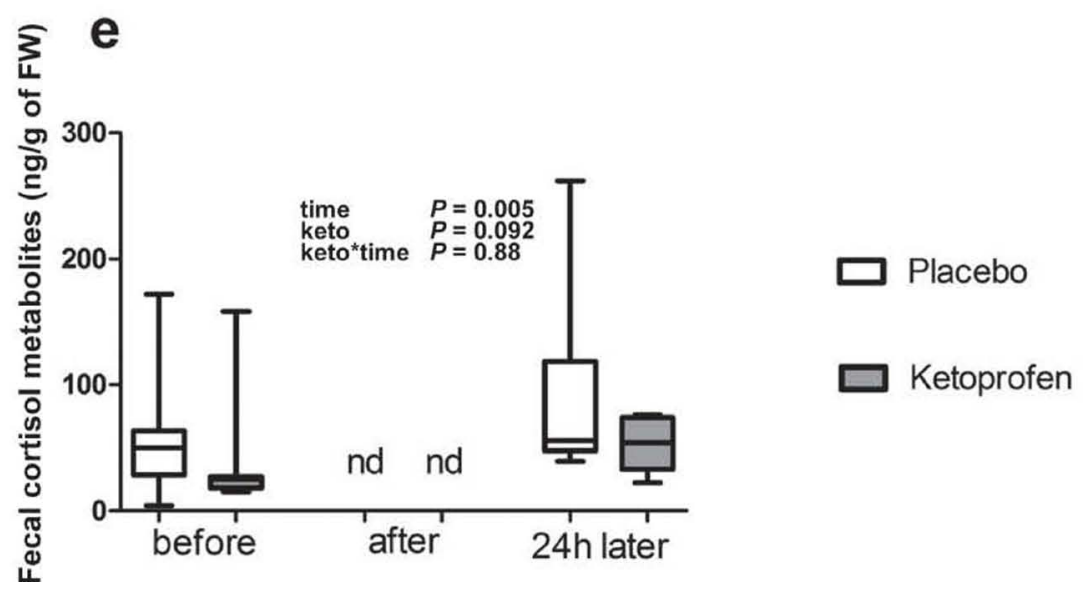

Figure 2. Box-and-whisker plots (median, box: 25/75 percentile, whisker: 5/95 percentile, dot: outlier) of concentrations of blood cortisol (a), glucose (b), fatty acids (c), lactate (d), and fecal cortisol metabolites (e) in lame cows either treated with ketoprofen $(\mathrm{n}=10)$ or placebo $(\mathrm{n}$ $=11$ ) before claw trimming and treatment of claw horn lesions in lateral recumbency (LR). Time line: before: 15 min before intervention; after: end of LR; $24 \mathrm{~h}$ after: $24 \mathrm{~h}$ after claw treatment. FW: fresh weight; nd: not determined. Significant difference at specific time points to baseline within group $\left(* * * P<0.001 ;{ }^{* *} P<0.01 ;{ }^{*} P<0.05\right)$. Different letters $(\mathrm{a}, \mathrm{b})$ indicate significant $(P \leq 0.05)$ differences within group at a specific time point. Global $P$-values [time, treatment (ketoprofen vs. placebo), and interactions] are indicated within graphs. 
Even slight interventions, as in cases of nonadvanced claw horn lesions in acute and mildly lame cows in this study, appear to be painful for affected cows. It has to be noted that the treating veterinarian avoided touching or putting pressure on the pain sensitive corium during the manipulation in the area of claw horn lesions in this study. Under practice conditions, with trimmers that are under constant time pressure, do not always have a high degree of professional training, or both, stress responses may be even stronger than observed in this study.

To detect cows with claw horn lesions at very early stages, twice weekly lameness scoring was performed. However, this does not exclude cows that had claw horn lesions that took longer to develop. Recently, it was reported that 1 to 2 wk before lameness was detected during lameness scoring, cows presented longer lasting resting periods and less frequent trough visits indicating discomfort, although they were not obviously lame (González et al., 2008; Chapinal et al., 2010; Yunta et al., 2012; Alsaaod et al., 2015). Thus, associated pain, even if low before detection of lesions by lameness scoring, may have sensitized the nociceptive system resulting in hyperalgesia (Whay et al., 1998, 2005; Laven et al., 2008), which may have contributed to increased hormonal and metabolic stress responses during the manipulations in lame cows.

The NSAID ketoprofen administered intramuscularly about 15 min before lame cows were turned into LR revealed neither numerically noticeable nor statistically significant effects on blood cortisol, glucose, and lactate concentrations or on behavioral responses on therapeutic claw trimming in lame cows. After therapeutic claw trimming, serum fatty acid concentrations were even significantly higher in ketoprofen-treated than in placebo-treated lame cows. However, in the view of the authors, analgesic properties of ketoprofen administered at the chosen dosage, route, and time of administration before therapeutic claw trimming appear not to be strong enough to abolish hormonal, metabolic, or behavior stress responses on treatment of claw lesions in mildly and acutely lame cows.

In earlier studies, the NSAID ketoprofen demonstrated (at the same dosage as in this study), in the recovery period after therapeutical claw trimming, analgesic effects as indicated by mild reduction of hyperalgesia (Whay et al., 2005), slight improvement of locomotion scores (O'Callaghan, 2002), better weight distribution between sound and lame legs (Flower et al., 2008; Chapinal et al., 2010), and a tendency of more activity and marginally higher milk yields in lame cows (O'Callaghan-Lowe et al., 2004a). In a recent study in acutely lame cows with claw horn lesions, cows were treated by a combination of therapeutic trim, a block on the opposing claw, and ketoprofen; cures were more likely than in cows receiving only foot trimming, or foot trimming combined either with a block on the opposing claw or only ketoprofen, which was attributed to the anti-inflammatory effects of NSAID treatment in addition to the effects of the block (Thomas et al., 2015). In this study, $24 \mathrm{~h}$ after the therapeutic claw trimming, fecal cortisol metabolites had a tendency to be lower in ketoprofen-treated compared with placebo-treated lame cows. Because fecal cortisol metabolites reflect longer lasting stress effects on animal's endocrine status (Ganswindt et al., 2010; Palme, 2012), the result may indicate analgesic effects of pre-emptive NSAID treatment in the early recovery period after treatment of claw horn lesions in mildly and acutely lame cows. Similar to previous research (O'Callaghan-Lowe et al., 2004a), the analgesic effects of NSAID on lameness scores in this study were not obvious, which may partially due the locomotion-altering effects of blocks on opposing claws of the treated limb (Cutler et al., 2015).

In conclusion, treatment of claw horn lesions in acutely and mildly lame cows as commonly performed by professional claw trimmers without anesthesia and analgesia appears to be painful for affected animals. Results provided no indications for a reduced stress response on claw treatment by pre-emptive application of the NSAID ketoprofen. In view of animal welfare aspects, adequate pain management appears obligatory while performing treatment of claw horn lesions. However, more studies are necessary to elucidate the severity of pain associated with treatments of claw horn lesions and on the development of adequate and adjusted pain management protocols for such interventions.

\section{ACKNOWLEDGMENTS}

The study was initiated by the authors and, upon request, financially supported by Merial SAS (29 Avenue Tony Garnier, Lyon 69007, France). Merial SAS exerted no influence on study design, evaluation and interpretation of results, or manuscript composition.

\section{REFERENCES}

Alsaaod, M., J. Niederhauser, G. Beer, N. Zehner, G. SchuepbachRegula, and A. Steiner. 2015. Development and validation of a novel pedometer algorithm to quantify extended characteristics of the locomotor behavior of dairy cows. J. Dairy Sci. 98:6236-6242.

Barker, Z. E., K. A. Leach, H. R. Whay, N. J. Bell, and D. C. Main. 2010. Assessment of lameness prevalence and associated risk factors in dairy herds in England and Wales. J. Dairy Sci. 93:932-941.

Becker, J., M. Reist, K. Friedli, D. Strabel, M. Wüthrich, and A. Steiner. 2013. Current attitudes of bovine practitioners, claw-trimmers and farmers in Switzerland to pain and painful interventions in the feet in dairy cattle. Vet. J. 196:467-476.

Becker, J., M. Reist, and A. Steiner. 2014. Factors influencing the attitudes of cattle veterinarians, farmers, and claw trimmers towards 
the pain associated with the treatment of sole ulcers and the sensitivity to pain of dairy cows. Vet. J. 200:38-43.

Blowey, R. W. 1990. A simple treatment for heel abscesses and deeper foot infections in cattle. Vet. Rec. 127:515-517.

Chapinal, N., A. M. de Passille, J. Rushen, and S. Wagner. 2010. Automated methods for detecting lameness and measuring analgesia in dairy cattle. J. Dairy Sci. 93:2007-2013.

Cutler, J. H., J. K. Shearer, D. F. Kelton, G. Cramer, P. J. Gorden, and S. T. Millman. 2015. An observational study of the effects of therapeutic hoof blocks on the locomotion, behavior, and production of healthy dairy cattle. J. Appl. Anim. Welf. Sci. 18:363-374.

Desrochers, A., and G. St Jean. 1996. Surgical management of digit disorders in cattle. Vet. Clin. North Am. Food Anim. Pract. $12: 277-298$.

El-Ghoul, W., and W. Hofmann. 2002. Einfluss von Klauenkrankheiten verschiedenen Grades auf die Höhe der messbaren Stressreaktionen unter besonderer Berücksichtigung von Cortisol und Laktat im Blutserum beim Rind. Prakt. Tierarzt 83:354-361.

Feist, M., R. Kostlin, and K. Nuss. 2008. Claw surgery in cattle: The benefit of perioperative analgesics. Tierarztl Prax Ausg G 36:367376

Flower, F. C., M. Sedlbauer, E. Carter, M. A. von Keyserlingk, D. J. Sanderson, and D. M. Weary. 2008. Analgesics improve the gait of lame dairy cattle. J. Dairy Sci. 91:3010-3014.

Ganswindt, A., S. Münscher, M. Henley, R. Palme, P. Thompson, and H. Bertschinger. 2010. Concentrations of faecal glucocorticoid metabolites in physically injured free-ranging African elephants Loxodonta africana. Wildl. Biol. 16:323-332.

González, L., B. Tolkamp, M. Coffey, A. Ferret, and I. Kyriazakis 2008. Changes in feeding behavior as possible indicators for the automatic monitoring of health disorders in dairy cows. J. Dairy Sci. 91:1017-1028.

Heppelmann, M., J. Kofler, H. Meyer, J. Rehage, and A. Starke. 2009. Advances in surgical treatment of septic arthritis of the distal interphalangeal joint in cattle: A review. Vet. J. 182:162-175.

Huxley, J. 2012. Lameness in cattle: An ongoing concern. Vet. J. 193:610-611

Laven, R. A., K. E. Lawrence, J. F. Weston, K. R. Dowson, and K. J. Stafford. 2008. Assessment of the duration of the pain response associated with lameness in dairy cows, and the influence of treatment. N. Z. Vet. J. 56:210-217.

Littell, R. C., J. Pendergast, and R. Natarajan. 2000. Tutorial in biostatistics: Modelling covariance structure in the analysis of repeated measures data. Stat. Med. 19:1819.

Main, D. C., Z. E. Barker, K. A. Leach, N. J. Bell, H. R. Whay, and W. J. Browne. 2010. Sampling strategies for monitoring lameness in dairy cattle. J. Dairy Sci. 93:1970-1978.

Mellor, D. J., and K. J. Stafford. 2004. Physiological and behavioural assessment of pain in ruminants: Principles and caveats. Pages 267-271 in Proc. Altern Lab Anim. June 2004. 32(Suppl. 1A):267271.

Murray, R. D., D. Y. Downham, M. J. Clarkson, W. B. Faull, J. W. Hughes, F. J. Manson, J. B. Merritt, W. B. Russell, J. E. Sutherst, and W. R. Ward. 1996. Epidemiology of lameness in dairy cattle: description and analysis of foot lesions. Vet. Rec. 138:586-591.

Nechanitzky, K., A. Starke, B. Vidondo, H. Müller, M. Reckardt, K. Friedli, and A. Steiner. 2016. Analysis of behavioral changes in dairy cows associated with claw horn lesions. J. Dairy Sci. 99:2904-2914

O'Callaghan, K. A. 2002. Lameness and associated pain in cattleChallenging traditional perceptions. In Pract. 24:212-219.

O'Callaghan, K. A., R. D. Murray, and P. J. Cripps. 2002. Behavioural indicators of pain associated with lameness in dairy cattle. Pages 309-312 in Proc. 12th Int. Conf. on Lameness in Ruminants. www. ivis.org, Orlando, FL.

O'Callaghan-Lowe, K. A., D. Y. Downham, R. D. Murray, and P. J. Cripps. 2004a. Effect of lameness treatment on pain and milk production in dairy cattle. Pages 237-238 in Proc. 13th Int. Symp. on Lameness in Ruminants. www.ivis.org, Maribor, Slovenia.
O'Callaghan-Lowe, K. A., R. D. Murray, P. J. Cripps, and W. R. Ward. 2004b. Working practices of cattle foot trimmers used for footcare in dairy cattle compared with those of veterinary surgeons for treatment of lameness in large animal practice. J. Vet. Med. A Physiol. Pathol. Clin. Med. 51:429-434.

Offinger, J., S. Herdtweck, A. Rizk, A. Starke, M. Heppelmann, H. Meyer, S. Janssen, M. Beyerbach, and J. Rehage. 2013. Postoperative analgesic efficacy of meloxicam in lame dairy cows undergoing resection of the distal interphalangeal joint. J. Dairy Sci. $96: 866-876$

Palme, R. 2012. Monitoring stress hormone metabolites as a useful, non-invasive tool for welfare assessment in farm animals. Anim. Welf. 21:331-337.

Palme, R., and E. Möstl. 1997. Measurement of cortisol metabolites in faeces of sheep as a parameter of cortisol concentration in blood. Z. Saugetierkd. 62(Suppl. 2):192-197.

Palme, R., C. Robia, S. Messmann, J. Hofer, and E. Möstl. 1999. Measurement of faecal cortisol metabolites in ruminants: A noninvasive parameter of adrenocortical function. Vet. Med. Austria 86:237-241.

Pesenhofer, G., R. Palme, R. M. Pesenhofer, and J. Kofler. 2006. Comparison of two methods of fixation during functional claw trimming - walk-in crush versus tilt table - in dairy cows using faecal cortisol metabolite concentrations and daily mil yield as parameters. Vet. Med. Austria 93:288-294.

Potterton, S., N. Bell, H. Whay, E. Berry, O. Atkinson, R. Dean, D. Main, and J. Huxley. 2012. A descriptive review of the peer and non-peer reviewed literature on the treatment and prevention of foot lameness in cattle published between 2000 and 2011. Vet. J. 193:612-616.

Pyman, M. 1997. Comparison of bandaging and elevation of the claw for the treatment of foot lameness in dairy cows. Aust. Vet. J. $75: 132-135$.

Rizk, A., S. Herdtweck, H. Meyer, J. Offinger, A. Zaghloul, and J. Rehage. 2012a. Effects of xylazine hydrochloride on hormonal, metabolic, and cardiorespiratory stress responses to lateral recumbency and claw trimming in dairy cows. J. Vet. Med. Assoc. 240:1223-1230.

Rizk, A., S. Herdtweck, J. Offinger, H. Meyer, A. Zaghloul, and J. Rehage. 2012b. The use of xylazine hydrochloride in an analgesic protocol for claw treatment of lame dairy cows in lateral recumbency on a surgical tipping table. Vet. J. 192:193-198.

Rushen, J., E. Pombourcq, and A. M. de Passille. 2007. Validation of two measures of lameness in dairy cows. Appl. Anim. Behav. Sci. 106:173-177.

Shearer, J. K., M. L. Stock, S. R. Van Amstel, and J. F. Coetzee. 2013. Assessment and management of pain associated with lameness in cattle. Vet. Clin. North Am. Food Anim. Pract. 29:135-156.

Sprecher, D., D. Hostetler, and J. Kaneene. 1997. A lameness scoring system that uses posture and gait to predict dairy cattle reproductive performance. Theriogenology 47:1179-1187.

Thomas, H., G. Miguel-Pacheco, N. Bollard, S. Archer, N. Bell, C. Mason, O. Maxwell, J. Remnant, P. Sleeman, and H. Whay. 2015. Evaluation of treatments for claw horn lesions in dairy cows in a randomized controlled trial. J. Dairy Sci. 98:4477-4486.

Toussaint Raven, E. 2003. Cattle Footcare and Claw Trimming. The Crowood Press Ltd., Marlborough, UK.

Van Amstel, S. R., and J. K. Shearer. 2006. Manual for Treatment and Control of Lameness in Cattle. 1st ed. Blackwell Publishing, Oxford, UK.

Whay, H. R., A. E. Waterman, A. J. Webster, and J. K. O'Brien. 1998 The influence of lesion type on the duration of hyperalgesia associated with hindlimb lameness in dairy cattle. Vet. J. 156:23-29.

Whay, H. R., A. J. F. Webster, and A. E. Waterman-Pearson. 2005. Role of ketoprofen in the modulation of hyperalgesia associated with lameness in dairy cattle. Vet. Rec. 157:729-733.

Yunta, C., I. Guasch, and A. Bach. 2012. Short communication: Lying behavior of lactating dairy cows is influenced by lameness especially around feeding time. J. Dairy Sci. 95:6546-6549. 